\title{
EDITORIAL \\ Training innovations in low- and middle-income countries
}

\author{
David Skuse ${ }^{\circ}$
}

Behavioural and Brain Sciences, Population, Policy and Practice UCL Great Ormond Street Institute of Child Health, 30 Guilford Street, London WC1N 1EH, UK. Email: d.skuse@ucl.ac.uk

Conflicts of interest None.

Keywords. Education and training; training innovations; psychiatric training.

\section{doi:10.1192/bji.2019.3}

(c) The Author 2019. This is an Open Access article, distributed Open Access article, distributed
under the terms of the Creative Commons Attribution-

NonCommercial-NoDerivatives licence (http://creativecommons. org/licenses/by-nc-nd/4.0/), which permits non-commercial re-use, permits non-com rercial re use, distribution, and reproduction in any medium, provided the original work is unaltered and is properly cited. The written permission of Cambridge University Press must be obtained for commercial re-use or in order to create a derivative work.

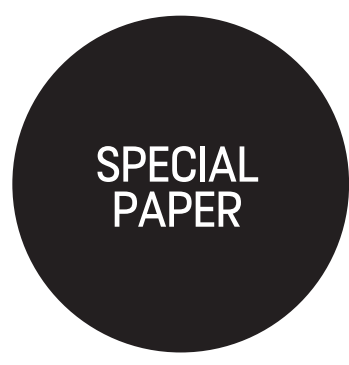

Is it feasible for a centre of excellence in another country to provide video-link training on managing psychiatric disorders to Low- and MiddleIncome Countries (LMICs) that lack the local infrastructure for such services? Our main theme in this issue discusses innovatory attempts to do so, with mixed results.

Salutary warnings are provided by Julian Leff in his fascinating contribution, drawn from lessons he learned when working as a transcultural psychiatrist in the WHO's International Pilot Study of Schizophrenia some years ago. Those lessons are likely to continue to be relevant today. He emphasises the observation that in many lower-income countries there is an attitude of caring acceptance of mental health problems, especially among extended families living in rural areas, which means that families expect to be involved in mental health interventions. A further lesson he learned is that if active treatment has been sought it may be (at least initially) provided by traditional healers who are trusted by the indigenous population and who are often well aware of the limitations of their expertise. Yassir Abbasi and colleagues attempted to provide a mental health awareness programme to Mogadishu, with the assistance of the Community Interest Company Praxis at their Evaluation and Research Institute in Liverpool. The course was delivered by audio/video link using volunteer tutors from a variety of backgrounds and professions. Somali participants comprised nurses, doctors and a few other professions allied to medicine. The aim was to raise awareness of mental health problems and their treatment in Somalia, a country that, as the authors describe, has a culturally derived lack of understanding of mental illness, yet a massive need for services. The success of this programme proved hard to evaluate objectively. Finally, we present a review from another UK-based group, Samantha Waterman and colleagues, who attempted to facilitate Group CBT by Skyping with healthcare workers in Sierra Leone. Their clients comprised 12 staff who had previously been employed to deal with Ebola cases. The purpose of this novel programme was to teach this small number of key individuals to deliver a Group CBT treatment programme to over 250 peers who may have been experiencing post-traumatic anxiety and depression as a consequence of their Ebola-related experiences. Barriers to the successful implementation of this programme are discussed; some of them were remarkably fundamental, such as the importance of providing a snack to group CBT participants who may have travelled long distances to attend. This was valued more than the reimbursement of their travel expenses.

\section{The lessons I learned as a psychiatrist from my transcultural work in low- and middle-income countries}

\author{
Julian Leff
}

Insititute of Psychiatry, London, UK. Email: julianpleff@gmail.com

Conflicts of interest: None.

doi:10.1192/bji.2017.35

(c) The Author 2018. This is an Open Access article, distributed Open Access article, distributed
under the terms of the Creative Commons Attribution-

NonCommercial-NoDerivatives

licence (http://creativecommons.
Transcultural observations offer an opportunity to study attitude to mental illness in different societies and family structures. The disparity between industrialised and lower-income societies reflects greater tolerance due to the ability of extended families to compensate for the patient's limitations.
My early work in London with families of people with schizophrenia was enriched by participation in the World Health Organization International Pilot Study of Schizophrenia (WHO IPSS), conducted in nine low- and middle-income countries. This gave me the opportunity to study the way in which families cope with mental illness in different societies and family structures.

Even in low-income societies, differences emerged between rural and urban domains. The 

permits non-commercial re-use, distribution, and reproduction in any medium, provided the original work is unaltered and is properly cited. The written permission of Cambridge University Press must be obtained for commercial re use or in order to create a derivative work. territory of Chandigarh in India offers a good example of this. In an agrarian area, the villagers live in extended families. But Chandigarh city, which has one of the highest per capita incomes in India, was designed by Le Corbusier to reflect a Western lifestyle, and residents live in nuclear family households. Patients in the surrounding countryside were found to do better owing to their inclusion in the community and participation in simple tasks, such as herding goats; in contrast, those in the city faced higher expectations and greater disappointment. Nonetheless, in urban environments too, support of the extended family and greater acceptance provides patients in lower-income societies with better conditions than those living on their own or in sheltered accommodation in higher-income societies.

For instance, in Varanasi, India, I was introduced to a family, which consisted of five sons who ran the family business in a multi-storey house. The bottom floor of the house was occupied exclusively by the men, while the many women and children were confined to the top floor. One of the brothers had schizophrenia. Every morning, all the men went down to the Ganges for a ritual bath. The young man with schizophrenia was always included among the brothers and they looked after him in a very caring way. He did not take part in the family business but otherwise lived an ordinary life among his family, which enabled him to feel that he really belonged even though he was not contributing economically.

This disparity between industrialised societies and lower-income areas reflects an attitude of caring acceptance regardless of disabilities. The indisputable importance of the family in contributing to better outcomes for people with schizophrenia is evidenced by the 5-year follow up of the WHO IPSS patients across different countries (Leff et al., 1992). The lower relapse rate for patients living with their families in lower-income societies, even when medication is unobtainable, is attributable to the supportive management of the illness by the relatives, their understanding of the patient's incapacities and lower expectations of her/his contribution to the family's wellbeing.

\section{Traditional healing}

In keeping with beliefs in low- and middle-income countries, people who are experiencing any kind of illness usually initially choose indigenous expertise over Western medicine (Leff, 1988). While undoubtedly charlatans exist, the strategies of traditional healers should not be scoffed at. They share the same ideology as their clients, who consist of not an isolated patient but the entire family or even clan. Whereas Western consultations tend to be private, confidential between the patient and doctor, traditional examinations take place with all relevant family members present. The best healers are very attuned to the cultural background of their clients and can 'divine' interpersonal relationships that are disguised as bodily complaints. For instance, a healer I encountered in Nigeria told me that if a man came to him with erectile problems, he would say suggestively, 'Here's the medicine, drink it daily and whatever you do stay away from your sister-in-law!' This tantalising injunction, referring to a local sexual taboo, is evidence of a psychologically astute understanding of erotic dynamics.

Much mental illness is ascribed to witchcraft, ancestral spirits or possession by harmful demons. Various local remedies and practices are used to engage with these, to placate or extract them. However, most healers I interviewed (through interpreters) distinguished between illnesses originating in local understandings and those necessitating Western medicine. For example, a healer I interviewed in Agra, India, told me that if a patient continued to be miserable despite indigenous treatments he would be sent for electroconvulsive therapy at the local hospital (where the family camped out in the grounds to provide meals and support for their ill relative). This shows that families are usually quite willing to accept a pragmatic composite of traditional and modern treatments. This flexible approach is more sophisticated than that of the Western-educated then-president of South Africa, who banned antiretroviral drugs in hospitals and advocated African onions as a cure for AIDS.

Similarly, a patient I saw in Ethiopia was brought in a catatonic state by his family, who had walked for many days from their far-off village. They said they had previously taken him to the Coptic church, where he was given holy water and beaten to exorcise the demon. When that did not seem to help, they put him in a cart and walked with him to Addis Ababa, to the one psychiatric hospital in the country, which serves 99 million people. Once given antipsychotic medication he rapidly recovered.

During my time in the IPSS, I was fortunate to see films and slides made by colleagues who had had access to indigenous ceremonies from many societies across the world. However weird some practices may seem, including trance states and exorcisms, they make sense in terms of local traditions, shared wisdom and beliefs about the source of illness and its extraction. For example, a film from Sri Lanka showed the exorcism of a demon which was held responsible for the illness of a woman in labour. The family of the patient called in a healer to perform this exorcism, which involved a very costly ritual of insistent drumming lasting from dawn to dusk. The patient was in fact suffering from pre-eclampsia. When the ceremony was completed to the satisfaction of the whole village, they took the patient to the local antenatal clinic, where she gave birth.

The family alone could not have afforded this ceremony, so their friends and neighbours contributed. This kind of solidarity is typical of many lower-income societies. Throughout Africa 
it is known as Ubuntu, meaning 'togetherness' or, as the locals put it, 'I am because you are'. A sentiment we seem to have forgotten.
Leff J., Sartorius N., Jablensky A., et al (1992) The International Pilot Study of Schizophrenia: five-year follow-up findings. Psychological Medicine, 22, 131-145.

\title{
References
}

Leff J. (1988) Psychiatry Across the Globe - A Transcultural View. The

Royal College of Psychiatrists.

\section{SPECIAL PAPER \\ Mogadishu calling: mental health awareness in Somalia via an innovative, live video-based mental health teaching programme established between Liverpool and Mogadishu}

\author{
Yasir Abbasi, ${ }^{1}$ James Forryan,, ${ }^{2}$ Abdi Ahmed, ${ }^{3}$ Paul Kypriano ${ }^{4}$ and \\ Rebecca Martinez ${ }^{5}$
}

\begin{abstract}
${ }^{1}$ Clinical Director for Addiction Services, Mersey Care National Health Service Foundation Trust, Liverpool; Email: dryiabbasi@ yahoo.com

${ }^{2}$ Foundation Year, Aintree University Hospital, Liverpool ${ }^{3}$ Project Manager, Mersey Care National Health Service Foundation Trust, Liverpool

${ }^{4}$ Senior Researcher, Praxis Evaluation and Research,

Liverpool

${ }^{5}$ Consultant Psychiatrist, Mersey Care National Health Service

Foundation Trust, Liverpool

Conflicts of interest. None.

doi:10.1192/bji.2017.30

(c) The Authors 2018. This is an Open Access article, distributed under the terms of the Creative Commons AttributionNonCommercial-NoDerivatives licence (http://creativecommons. org/icenses/by-nc-nd/4.0/), which org/licenses/by-nc-nd/4.0/), whic permits non-commercial re-use, distribution, and reproduction
any medium, provided the original work is unaltered and is properly cited. The written permission of Cambridge University Press must be obtained for comPress must be obtained for com-
mercial re-use or in order to create a derivative work.
\end{abstract}

In 2013 the Federal Government of Somalia contacted the Mersey Care National Health Service Foundation Trust (MCFT), asking whether they could formulate a teaching programme tailored towards improving mental health provision in Somalia, and the E-learning Mental Health Training Programme (SOM-Health) was eventually conceived. The fundamental aim was to provide mental health awareness to practitioners and trainees in Somalia so that they could deliver mental healthcare services confidently and effectively.

\section{Background}

Somalia has a population of 11265116 (in 2017), with a total life expectancy of 55 years (WHO, 2015; Worldometers.info, 2017). There are few mental health services in Somalia, which is incongruous to the country's need. Since the outbreak of civil war in 1991, the country has been plagued by conflict and unrest. A huge number of Somali citizens have been subjected to torture, beatings, rape and have suffered life-changing injuries; others will have witnessed such atrocities being committed to loved ones and friends. Many mental health diagnoses can be traced back to substance misuse involving khat, the leaves traditionally consumed in Somalia that are laden with the amphetamine-like chemical cathinone (WHO, 2010). Unsurprisingly, the World Health Organization (WHO) reports that one in three Somalis have been affected by some form of mental illness (this figure exceeds that seen in other comparable low-income countries) (WHO, 2011). Furthermore, a culturally derived lack of understanding of mental illness compounds the issue. Through misconceptions and sometimes antiquated cultural beliefs, people with mental illness are often ostracised, stigmatised and even imprisoned or chained against their will (Hooper, 2013). In fact, between 2000 and 2010, 90\% of mental health patients had been subjected to at least one episode of chaining, a practice both ubiquitous and indeed endorsed in many mental health facilities within Somalia (WHO, 2010).

\section{Scoping report}

The initial scoping report, conducted in October 2013 (and updated in June 2015), was carried out by Praxis.

\section{Safety}

Outcomes underlined that an 'on the ground' programme would not be feasible in light of the endemic political and security situations precluding the travel of staff to Somalia. Nevertheless, the scoping report felt that teaching and assistance via distance learning remained extremely viable, especially with the improvements in technology and internet access in Somalia.

\section{Models}

Praxis identified the work of the King's Tropical Health and Education Partnership (KTSP) as a potential blueprint that Mersey Care National Health Service Foundation Trust (MCFT) could reproduce. KTSP has developed basic psychiatry courses for final year medical students at two partner universities and peer-to-peer learning sessions for both medical students and nursing students (THET, 2002; WHO, 2013). 